\title{
CDISC Standard
}

National Cancer Institute

\section{Source}

National Cancer Institute. CDISC Standard. NCI Thesaurus. Code C142416.

A standard set of data models, controlled vocabularies, and exchange standards developed by the Clinical Data Interchange Standards Consortium (CDISC), and intended to address the life-cycle of clinical trial development and electronic submission of clinical data; including protocol representation, data collection, tabulation, and analysis. 